\title{
Pathophysiological Concepts in Multiple Sclerosis and the Therapeutic Effects of Hydrogen Sulfide
}

\author{
Fatemeh Talaei $^{1}$
}

1. Novel Drug Delivery Systems Lab, Faculty of Pharmacy, Tehran University of Medical Sciences, Tehran, Iran.

Citration: Talaei, F. (2016). Pathophysiological concepts in multiple sclerosis and the therapeutic effects of hydrogen sulfide. Basic and Clinical Neuroscience, 7(2), 121-136. http://dx.doi.org/10.15412/J.BCN.03070206

http://dx.doi.org/10.15412/J.BCN.03070206

Article info:

Received: 20 April 2015

First Revision: 02 July 2015

Accepted: 05 September 2015
Key Words:

NaHS, Fibronectin, Myelin, Astrocytes, Oligodendrocytes, HUVEC, Peripheral Blood Mononuclear Cells

\begin{abstract}
A B S T RA C T
Introduction: Multiple sclerosis (MS) is generally known as a manageable but not yet curable autoimmune disease affecting central nervous system. A potential therapeutic approach should possess several properties: Prevent immune system from damaging the brain and spinal cord, promote differentiation of oligodendrocyte progenitor cells (OPCs) into mature oligodendrocytes to produce myelin, prevent the formation of fibronectin aggregates by astrocytes to inhibit scar formation, and enhance function of healthy endothelial cells (ECs).

Methods: To determine if an increase in sulfur contents through $\mathrm{H}_{2} \mathrm{~S}$, a potent antioxidant known to induce protective autophagy in cells, could provide the above desired outcomes, peripheral blood mononuclear cells (PBMNCs), OCPs, astrocytes, and ECs were treated with NaHS (50 $\mu \mathrm{M})$ in vitro.

Results: Transmigration assay using EC monolayer showed that serotonin increased migration of PBMNC while pretreatment of EC with NaHS inhibited the migration induced by serotonin treatment. NaHS upregulated proteins involved in immune system response and downregulated PBMNCs- and EC-related adhesion molecules (LFA-1 and VCAM-1). Furthermore, it had a cell expansion inducing effect, altering EC morphology. The effects of NaHS on OPCs and astrocytes were studied compared to mTOR inhibitor rapamycin. In NaHS treated astrocytes the induced fibronectin production was partially inhibited while rapamycin almost fully inhibited fibronectin production. NaHS slowed but did not inhibit the differentiation of OCPs or the production of myelin compared to rapamycin.
\end{abstract}

Conclusion: The in vitro results point to the potential therapeutic application of hydrogen sulfide releasing molecules or health-promoting sulfur compounds in MS.

\section{Introduction M ultiple sclerosis (MS) is an inflamma- tory disease where reactive oxygen spe- cies (ROS) involved in the insulation of the nerve cells in the brain and spinal cord become irreversibly damaged, disrupting}

the communication between the different components of the nervous system. This process will result in a wide range of signs and symptoms with the most common being the paresthesias. Motor and autonomic spinal cord symptoms develop depending on the severity of the immune reaction as well as the location and extent of the plaques. The pathophysiology of MS involves several components such as vascular,

\footnotetext{
* Corresponding Author:

Fatemeh Talaei, PhD

Address: Novel Drug Delivery Systems Lab, Faculty of Pharmacy, Tehran University of Medical Sciences, Tehran, Iran.

Tel: +98 (21) 66959052

Fax: $+98(21) 6695905$
}

E-mail:Talaei@irimc.org 
redox, neurodegenerative, and inflammatory/autoimmune (Miljkovic \& Spasojevic, 2013).

The main protecting barriers of nervous system are endothelial cells (ECs), which are connected by tight junctions so that most molecules cannot penetrate it. During MS attack, blood-brain barrier (BBB), which normally makes nervous system inaccessible to the white blood cells, gets damaged, allowing white blood cells to cross over and attack myelin sheath (Waubant, 2006). Perivascular infiltration of inflammatory mononuclear cells is a characteristic of MS plaques. Thus, MS has been suggested as a disease of the BBB, which its weakening may be due to disturbance in the ECs of the blood vessel. Local inflammatory response is initiated by activated $\mathrm{T}$ cells, which infiltrate the CNS, leading to glial cell activation with further recruitment of mononuclear cells (Alirezaei, Kemball, \& Whitton, 2011). The excessive release of glutamate, which indirectly increases the level of intracytosolic Ca2 (Matute et al., 2007), and increasing levels of iron in MS (Stephenson, Nathoo, Mahjoub, Dunn, \& Yong, 2014) are highly toxic to both neurons and oligodendrocytes. These events lead to demyelination, axonal injury, and cortical neuronal loss. Neurodegeneration appears to be an important part of MS, becoming dominant in the latter stages. Pathological studies of newly developed lesions have demonstrated that myelin disintegration precedes the invasion of the immune system indicating the secondary involvement of the immune action in MS.

The course of MS could be partially changed by drugs such as interferon beta 1a, teriflunomide, fingolimod, mitoxantrone, dimethyl fumarate, and natalizumab. They suppress the immune system to slow down the attack on myelin sheath and progression of MS to prevent its relapses. Although immune suppressants are the best medications available against MS, dissatisfaction with the autoimmune model has grown as new observations, which cannot be easily explained by the model, have accumulated.

Antioxidants are known to have beneficial effects on MS (Carlson \& Rose, 2006). Redox processes and reactive species seem to be highly involved in MS pathogenesis and their modulation could prevent MS, an early treatment that target specific pathophysiological components of the heterogeneous mechanisms of MS. In this context, $\mathrm{H} 2 \mathrm{~S}$ as one of the most important antioxidants mainly produced by cystathionine beta synthase (CBS) in nervous system (Talaei et al., 2014) could highly affect cells involved in MS pathogenesis. Importantly, mutant variants of CBS may be associated with the age of MS onset (Ineichen et al., 2014) and the elevated levels of homocysteine observed in CBS deficiency could increase BBB permeability (Kamath et al., 2006) and thus the pharmacological modulation of this enzyme or its by- products could provide preventive and therapeutic strategies in MS. The role of $\mathrm{H}_{2} \mathrm{~S}$ in modulating leukocyte adhesion to the vascular endothelium, leukocyte infiltration, edema formation, and EC protection has been previously studied. These studies implicate $\mathrm{H}_{2} \mathrm{~S}$ as an important endogenous inhibitor of key elements of acute inflammatory reactions. For example, platelets are more active in MS patients, showing increased adhesiveness (Sheremata et al., 2008), and play a crucial role in the promotion of CNS inflammation in experimental autoimmune encephalomyelitis (EAE) (Langer et al., 2012). $\mathrm{H}_{2} \mathrm{~S}$ may inhibit human platelet aggregation in part by closing gaps of intercellular communication. Interestingly, platelet serotonin has a modulator effect on immune system (Duerschmied et al., 2013) and also regulates $\mathrm{H}_{2} \mathrm{~S}$ in cells through CBS upregulation while serotonin induced CBS upregulation is inhibited by rapamycin (Talaei et al., 2011). Thus, studying the effects of $\mathrm{H}_{2} \mathrm{~S}$ on serotonininduced immune system activity could provide further clues to potentially beneficial effects of this molecule in MS and strengthen our understanding of the molecular interactions involved.

Acommon feature of many neurodegenerative diseases such as MS is protein aggregation. $\mathrm{H}_{2} \mathrm{~S}$ regulates proteostasis and inhibits protein aggregation (Talaei, 2014; Talaei, 2012). Several studies support the notion that mTOR (mammalian target of rapamycin) a serine/threonine protein kinase (Dello Russo, Lisi, Feinstein, \& Navarra, 2013) regulates proteostasis involved in microglial proinflammatory activation, and its inhibition in glial cells results in anti-inflammatory actions (Kitagishi, Kobayashi, Kikuta, \& Matsuda, 2012; Lisi, Navarra, Feinstein, \& Dello Russo, 2011), suggesting possible beneficial effects of mTOR inhibitors (like rapamycin) in the treatment of inflammatory-based pathologies of the central nervous system. However, mTOR plays an important role in the regulation of oligodendrocyte development and myelination process as well as several neuronal functions (Tyler et al., 2009), which may highly limit such therapeutic approach. Nevertheless, there is robust evidence that rapamycin ameliorates the clinical course of both the relapsing-remitting and chronic EAE, as well as significantly reduces the hyperalgesia observed before its clinical development (Dello Russo et al, 2013). The relationship between autophagy, inflammation, and neurodegenerative diseases is complex (Alirezaei, Kemball, \& Whitton, 2011). Regulation of autophagy may prevent, delay, or ameliorate some of these disorders by clearing the antigenic particles (Talaei et al., 2014). Regulation of $\mathrm{H}_{2} \mathrm{~S}$ levels, thus, might have clinical implications for the treatment of immune-mediated neurodegenerative diseases such as MS provided that modulation of the kinases involved in autophagy pathways would not negatively impact cellular and tissue repair mechanisms. 
Unfortunately, the current immune-based therapies have little, if any, effect on MS progression. This situation calls for introduction and development of new molecules or therapeutic systems, which could tackle this important issue. The main cells involved in pathophysiology of MS are oligodendrocytes, astrocytes, endothelial cells, and the lymphocytes (T and B). Thus, the goals in MS treatment include inhibition of fibronectin production by astrocytes to prevent scar/ plaque/lesion formation while maintaining myelin production by oligodendrocytes. This should be accompanied by prevention of leukocyte migration into central nervous system through modulation of EC function and inhibition of immune system response. It was hypothesized that hydrogen sulfide (NaHS), which is naturally produced by cells and has crucial impact on different systems inside the body, could be a rational therapeutic choice to achieve the above goals, and provide preventive and therapeutic strategies against MS. In the present study, the effects of NaHS on different cell types involved in MS pathophysiology were carefully evaluated and discussed.

\section{Materials and Methods}

\subsection{Cell culture and cell treatments}

Peripheral blood mononuclear cells (PBMNCs) were separated from the whole blood obtained from healthy volunteers by a density gradient centrifugation method using Ficoll Histopaque through manufacturer's protocol and described by Panda et al. (Panda et al., 2012). Cells were cultured in LYMPH Zenbio medium.

\subsection{Serotonin treatment of PBMNCs}

To emulate potential inflammatory effects of serotonin released in central nervous system in MS, serotonin $(0.3 \mu \mathrm{mol})$ dissolved in cell medium was added to PBMNC (2x106/ well) in 6-well plates. Cell samples were taken at $15 \mathrm{~min}$ utes and 60 minutes, centrifuged at $500 \times \mathrm{g}$ for 5 minutes. The medium was separated and the cells were either placed on cover glasses for fixation and immunohistochemical analysis or frozen at $-80^{\circ} \mathrm{C}$ following lysis for later Western blot analysis.

\subsection{Cell lysis}

Frozen samples were homogenized $(20 \% \mathrm{w} / \mathrm{v})$ in ice-cold radioimmunoprecipitation assay (RIPA) buffer (1\% IGEPAL CA-630 [octylphenylpolyethylene glycol], 1\% sodium dodecyl sulfate, $5 \mathrm{mg} / \mathrm{mL}$ sodium deoxycholate, $1 \mathrm{mmol} / \mathrm{L}$ sodium orthovanadate, $40 \mu \mathrm{g} / \mathrm{mL}$ phenylmethylsulfonyl fluoride, $100 \mu \mathrm{g} / \mathrm{mL}$ benzamidine, $500 \mathrm{ng} / \mathrm{mL}$ pepstatin A, $500 \mathrm{ng} / \mathrm{mL}$ leupeptin and $500 \mathrm{ng} / \mathrm{mL}$ aprotinin in [phos- phate buffer solution] PBS). The protein concentration was determined in lysates by Bradford protein assay (Bradford, 1976).

\subsection{PBMNCs transmigration assay with modified Boyden chamber}

To prepare conditioned medium to stimulate PBMNCs migration, lipopolysaccharide (LPS) was reconstituted in an endotoxin-free saline (Sigma Chemical Co.). Prior to cell stimulation, LPS was sonicated for 10 minutes in a water bath sonicator. PBMNCs $(10 \times 106)$ were incubated in the presence of LPS $(0.1 \mu \mathrm{g} / \mathrm{mL})$. Stimulation was performed for 5 hours in a $5-\mathrm{mL}$ sterile tube at $37^{\circ} \mathrm{C}$ in a humid $5 \% \mathrm{CO}_{2}$ atmosphere. Cell samples were then centrifuged $\left(1000 \times \mathrm{g}\right.$, for 10 minutes, at $\left.24^{\circ} \mathrm{C}\right)$, and the resulted supernatants (conditioned media) were used in PBMNC transmigration assays.

For transmigration assays, the supernatants of LPS-treated PBMNCs were passed through a 1-mL polymyxin B column to remove the endotoxin. PMNCs transmigration assay was carried out in a Boyden chamber system with some modifications. Briefly, cell culture inserts $(3-\mu \mathrm{m}$ pore size) were used to form dual compartments in a Falcon 24-well culture plate. The polyethylene membrane filters $(6.4-\mathrm{mm}$ diameter) of the inserts were coated successively with $1 \%$ (w/v) gelatine (overnight), $0.006 \%(\mathrm{v} / \mathrm{v})$ stabilized human fibronectin (for $2 \mathrm{~h}$ ), and $15 \times 104$ primary endothelial cells (HUVEC) (for $2 \mathrm{~d}$ ). When the endothelial cells were confluent, conditioned media $(0.7 \mathrm{ml})$ were loaded to the lower compartment of the Boyden chamber and the freshly isolated human BPMNCs $(1 \times 106$ cells in $0.2 \mathrm{~mL} 5 \% \mathrm{FBS}$ in RPMI 1640) were loaded on the human umbilical vein endothelial cell (HUVEC) monolayer.

In another experiment, PBMNCs were treated with serotonin $(0.3 \mu \mathrm{mol})$ in $0.2 \mathrm{~mL} \mathrm{5 \%} \mathrm{FBS} \mathrm{in} \mathrm{RPMI} 1640$ before being loaded on HUVEC to study the potential effect of this molecule (involved in MS pathology) on transmigration of PBMNCs. Furthermore, the effect of the addition of NaHS $(50 \mu \mathrm{mol})$ and serotonin $(0.3 \mu \mathrm{mol})$ at the same time was studied on PBMNCs transmigration after 1 hour pretreatment of EC with NaHS (50 $\mu \mathrm{mol})$. PBMNCs were allowed to migrate for 2 hours at $37^{\circ} \mathrm{C}$ and $5 \% \mathrm{CO}_{2}$. The cells that crossed the HUVEC layer were collected from the lower compartment and counted using a hemocytometer.

\subsection{Cystathionine- $\beta$-synthase siRNA}

The expression of $\mathrm{H}_{2} \mathrm{~S}$ producing enzyme, CBS, was blocked in PBMNC by application of a predesigned siRNA (sc-60335, Santa Cruz) using a low speed centrifuge method 
to enhance transfection. PBMNCs were counted and placed in 6-well plates in antibiotic-free normal growth medium supplemented without fetal calf serum (FCS). Freshly isolated cells were transfected using lipofectamine 2000 (Invitrogen) at a final concentration of 100 pmol siRNA in $5 \mu \mathrm{L}$ lipofectamine for each well in a 6-well plate. Plates were centrifuged at $1000 \mathrm{rpm}$ for 30 minutes at $37^{\circ} \mathrm{C}$ followed by incubation at $37^{\circ} \mathrm{C}$ in $5 \% \mathrm{CO}_{2}$ atmosphere. After 12 hours, the cells were centrifuged and the medium was changed to the medium containing antibiotics and FCS. Cells were left for 2 hours at $37^{\circ} \mathrm{C}$. Then, control cells and siRNA-treated cells were incubated with serotonin and NaHS as described previously to evaluate the effect of CBS inhibition on serotonin-induced PBMNCs transmigration through endothelial cell layer. Additional siRNA-treated cells were used to evaluate the expression of adhesion molecule, integrin LFA-1 (lymphocyte function-associated antigen 1), known to bind with ICAM-1 on EC and promote leukocyte transmigration.

\subsection{Isolation of oligodendrocyte progenitor cells and cell treatment}

Oligodendrocyte progenitor cells (OPCs) were obtained from 1- to 3-day-old Wistar rats (Harlan) brain with a shakeoff method as described previously (Bsibsi, Nomden, van Noort, \& Baron, 2012) and cultivated on poly-l-lysinecoated 10 -cm dishes $(1.0 \times 106 /$ dish $)$ with or without glass cover slips as described previously (Maier et al., 2005) in Sato (Maier, Baron, \& Hoekstra, 2007) and brain nutrients medium. Cells were kept at $37^{\circ} \mathrm{C}$ in $5 \% \mathrm{CO}_{2}$ atmosphere. The OPCs were first synchronized in Sato medium supplemented with platelet-derived growth factor-AA (Peprotech; $10 \mathrm{ng} / \mathrm{mL}$ ) and fibroblast growth factor-2 (Peprotech, $10 \mathrm{ng} /$ $\mathrm{mL}$ ) for 2 days. Differentiation was induced by growth factor withdrawal and cells were grown for 5 days in Sato medium containing $0.5 \%$ fetal calf serum with either rapamycin $(20 \mathrm{nM})$, or NaHS $(50 \mu \mathrm{M})$, or none. The medium was changed every 30 hours. Cells on coverslips were acetone fixed for immunohistochemical studies. The rest of the cells were washed and homogenized and stored as previously described. Cells on coverslips were acetone fixed for myelin basic protein (MBP) immunohistochemical analysis.

\subsection{Isolation and treatment of astrocytes}

Astrocytes were isolated from corpus callosum or subcortical white matter of Wistar rats and cultured as described previously (Bsibsi, Ravid, Gveric, \& van Noort, 2002). The purity of the cultures was routinely verified by staining for GFAP. Astrocyte cultures used were at least $97 \%$ pure. The cells were plated in 10 -cm dishes $(1.0 \times 106 /$ dish $)$ or 6 -well plates containing glass coverslips (10000/well). To increase fibronectin production and stimulate fibronectin aggrega- tion as reported in MS, Poly (I:C) (polyinosinic-polycytidylic acid, a synthetic ds-RNA molecule designed to mimic RNA virus infection) $(10 \mu \mathrm{g} / \mathrm{mL})$ was introduced into the cells using lipofectamine 2000 according to the manufacturer's protocol (Invitrogen, UK). After 24 hours, at $37^{\circ} \mathrm{C}$, the supernatant was replaced with FBS containing normal cell medium and the cells were left to proliferate for another 24 hours at $37^{\circ} \mathrm{C}$. The supernatant was then replaced with medium containing rapamycin $(20 \mathrm{nM})$ or NaHS (50 $\mu \mathrm{M})$ and normal medium to serve as control. The cells were treated for 5 days and the medium was changed every 30 hours. Cells on coverslips were acetone fixed for immunohistochemical analysis of fibronectin. Other samples were used to study cell viability or stored at $-80^{\circ} \mathrm{C}$ after lysis for later Western blot analysis.

\subsection{Human umbilical vein endothelial cell (HU-} VEC) isolation

HUVECs were isolated from human umbilical vein as described by Steve P. Crampton (Crampton, Davis, \& Hughes, 2007), cultured in EC medium and incubated at $37^{\circ} \mathrm{C}$ with $5 \% \mathrm{CO}_{2}$ overnight. Then, 6-well plates were coated with $0.1 \%$ gelatin and cultured with HEC medium. Single cells were treated with $\mathrm{NaHS}(50 \mu \mathrm{M})$ and the cell area was measured by ImageJ after capturing images of the cells under a light microscope at different time points. To analyze the effect of NaHS on VCAM-1, HUVECs were pretreated with NaHS $(50 \mu \mathrm{M})$ for 1 hour prior to stimulation with conditioned medium and then samples were harvested to analyze VCAM-1 expression. The rest of the protein expression evaluations were conducted after 1 hour of NaHS $(50 \mu \mathrm{M})$ treatment without conditioned medium.

\subsection{Immunohistochemistry and microscopy}

For immunohistochemical examination, cells were fixed by acetone (100\%) for 10 minutes, then washed and rehydrated with phosphate buffer solution (PBS). Hydrogen peroxidase activity was blocked by hydrogen peroxide (1\%) in PBS for 30 minutes, washed with PBS 3 times for 5 minutes each and incubated for 1 hour with $1 \%$ primary antibody in PBS containing 1\% bovine serum albumin (BSA) for 1 hour. Next, it was washed in PBS thrice and incubated with $1 \%$ secondary antibody in PBS containing $1 \%$ BSA for 1 hour. The slides were washed in PBS and in the next step, Dako $\mathrm{AEC}^{+}$high sensitivity substrate chromogen (Dako, Denmark) was used to visualize protein bond antibody. To show myelin stain, a fluorescent second antibody (1100) with $1 \%$ BSA and $1 \%$ rat serum was used. Dako fluorescence mounting medium with DAPI was used to visualize myelin stains. Images were captured using either a light or a fluorescent microscope. 


\subsection{Western blotting}

The expression of proteins was quantified by Western blot method. In brief, cells were washed with PBS and lysed in $120 \mu \mathrm{L}$ RIPA buffer. Loading buffer $(20 \mu \mathrm{L})$ was added to every $50 \mu \mathrm{g}$ of cell protein and ran at $100 \mathrm{~V}$ for 60 minutes. Proteins were transferred to a nitrocellulose membrane, probed by antibodies and detected by West Pico Chemiluminescent Substrate (supersignal), then photographed and analyzed with Gene Tools software, version 3.08 (Syngene, UK). Protein expression was corrected over $\beta$-actin as an internal reference.

\subsection{Antibodies}

Antibodies used in this study were as follows: Fibronectin antibody (Santa Cruz, sc-6952), Myelin antibody against myelin basic protein (MBP abcam 78157), SOCS-3 (H-103), sc9023, IL-10 (M-18), sc-1783, CBS (Santa Cruz SC-46830), IL-10 (Novus Biologicals, NB100-63262), Integrin $\beta 2 / L F A-$ 1 (Cell applications, CG1286), V-CAM (VCAM-1 Antibody (C-19)): sc-1504, HO-1 (Heme Oxygenase 1 Antibody (H105): sc-10789.

\subsection{Statistical analysis}

The statistical data analyses were performed using 1-way ANOVA with Tukey test or unpaired $t$ test with Welch correction. Statistical significance difference was accepted at $\mathrm{P}<0.05$ (GraphPad Prism version 5).

\section{Results}

\subsection{Effects of NaHS and serotonin on PMNCs}

Platelets are more active in patients with MS and platelet serotonin induces immune system activity and immune cell transmigration. In this regard, transmigration assay was performed to evaluate the effects of $\mathrm{NaHS}$ and serotonin treatment on PBMNCs transmigration across EC barrier representing BBB. Endothelial cells such as HUVEC, functionally express blood brain barrier (BBB) properties and are useful surrogates to study leukocyte-endothelial cell interactions at BBB (Man et al., 2008). PBMNCs were treated with serotonin to imitate the potential effects of serotonin present at MS lesions and then the counter effects of NaHS on cell migration were studied. Boyden assay showed that $60 \%$ of the PBMNCs treated with serotonin, migrate across the filter compared to $25 \%$ migration observed in untreated cells (Figure 1A). Treatment of PBMNCs with NaHS that releases high levels of $\mathrm{H}_{2} \mathrm{~S}$, decreased PBMNCs transmigration of both control and serotonin treated cells, while cystathionine beta synthase (CBS) knockout decreased PBMNC transmi- gration and serotonin treatment of CBS knockout cells significantly increased transmigration percentage (Figure $1 \mathrm{~A}$ ).

Cytokine signaling inhibitors and inhibitory cytokines, significantly inhibit cell-cell signaling in immune system with anti-inflammatory properties. NaHS effect was studied on two important inhibitory factors known as IL-10 and SOCS3. NaHS upregulated IL-10 (Figure 1B), a cytokine synthesis inhibitory factor and SOCS-3 (suppressor of cytokine signaling 3) expression of PBMNCs compared to control (Figure $1 \mathrm{C}$ ) suggesting its immune system inhibitory effects. Serotonin upregulated CBS in PBMNCs (Figure 1 E, F) compared to untreated cells (Figure 1D, F). CBS upregulation was noted in Western blot samples 15 minutes after the addition of serotonin and increased further at 60 minutes (Figure 1F). Upregulation of adhesion of molecules indicates higher potential for transmigration. The effect of NaHS on integrin LFA-1 (adhesion molecule) expression was studied too. While NaHS inhibited the observed upregulation, treatment of PBMNCs with serotonin upregulated integrin LFA-1. CBS knockout significantly upregulated integrin LFA-1 (ICAM-1 binding adhesion molecule) expression in PBMNCs, while NaHS downregulated both CBS knockout and serotonininduced upregulation of this protein (Figure 1G). Addition of serotonin to CBS knockout cells highly increased the expression of LFA-1 on these cells (Figure 1G) further pointing to the regulatory effects of CBS on PBMNCs molecule adhesion expression and its potential immune system inhibitory effect. Serotonin-treated and-untreated cells transfected with negative control siRNA (AM4644, Ambion)-lipofectamine, did not show any different results compared to serotonintreated and -untreated control cells and thus were not included in charts to prevent distraction from the significant results.

\subsection{Effects of NaHS compared to rapamycin on as- trocytes}

Higher production of fibronectin by astrocytes in MS induces myelin replacement and scar formation. Astrocytes were treated with poly $(\mathrm{I}: \mathrm{C})$ to increase fibronectin production or aggregation and later treated with NaHS and rapamycin to evaluate the effects of these molecules. Ploy (I:C) increased fibronectin production in astrocytes (Figure $2 \mathrm{~B}$, E) compared to untreated cells (Figure 2A, E). Cells treated with rapamycin (mTOR inhibitor) showed almost full inhibition of fibronectin production by poly (I:C)-treated astrocytes (Figure 2C, E), while NaHS treatment showed a decrease in fibronectin production by poly (I:C)-treated astrocytes (Figure 2D, E). Rapamycin and NaHS toxic effects did not affect cell viability of astrocytes after w120 hours (Figure 2F) as shown by Trypan Blue cell count caused by lowered cell division compared to control cells (Figure $2 \mathrm{G}$ ). 

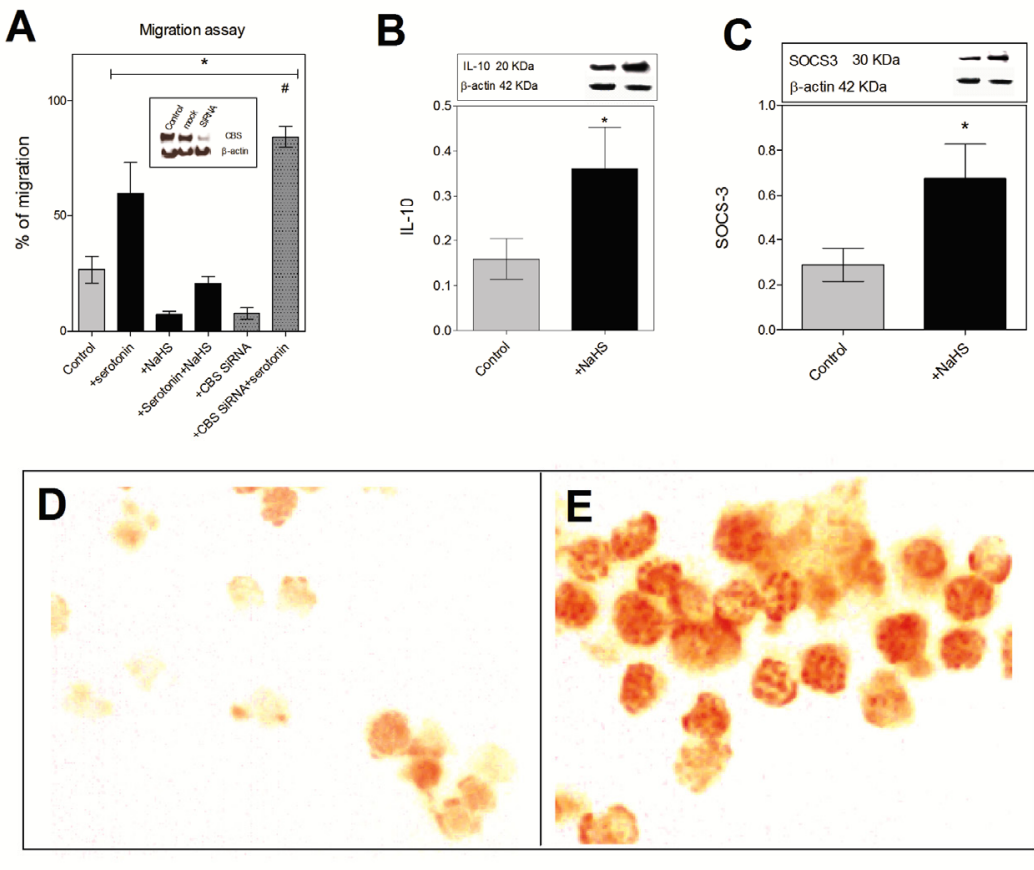

CBS expression in non treated PBMNCs

$\mathbf{F}$

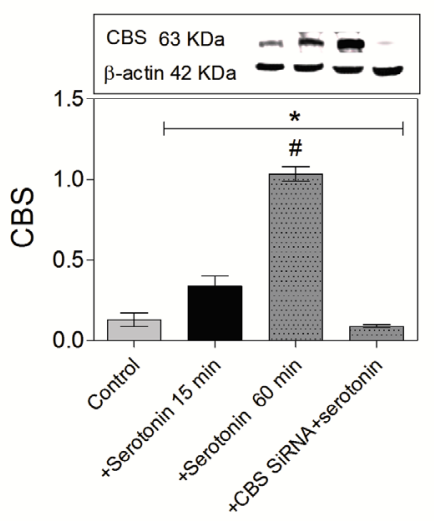

CBS expression in serotonin treated PBMNCs

G

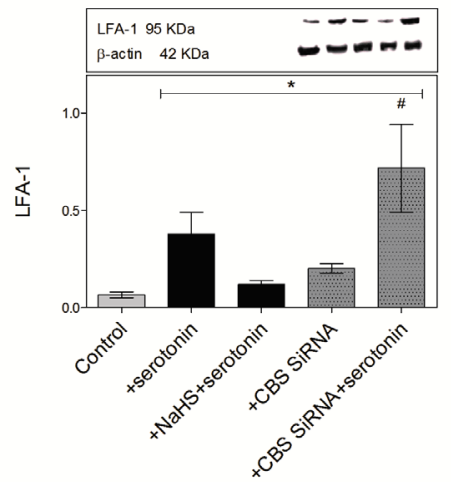

NEUR:SCIENCE

Figure 1. Effect of serotonin on peripheral blood mononuclear cells (PBMNCs), A) Transmigration of PBMNCs subjected to different treatments across endothelial cells (EC), B) IL-10 expression by PBMNCs through NaHS treatment, C) SOCS3 (suppressor of cytokine signaling), 3) Expression by PBMNCs through NaHS treatment, D) CBS (cystathionine beta synthase) immunohistochemical analysis in untreated PBMNCs, E) CBS immunohistochemical analysis in serotonin treated PBMNCs (1 hour), F) CBS expression in PBMNCs at 15 minutes and 1 hour after serotonin treatment and after CBS knockout, G) Integrin LFA-1 expression where PBMNCs were subjected to different treatments.

Data are presented as means $\pm \mathrm{SD}$ ( $\mathrm{n} \geq 3$ per group in 3 replicate experiments). * Difference to control cells. \# Difference to CBS siRNA treated cells (significant difference between dotted bars). $P<0.05$. Western blot expression is normalized to $B$-actin; lanes of Western blot insets are in the same order as in the X-axis.

\subsection{Effects of NaHS compared to rapamycin on OPCs and OLGs}

OPCs differentiate into mature oligodendrocytes (OLGs) and produce myelin. In MS, OLGs got damaged and remaining ones fail to fully remyelinate CNS lesions. OPCs (Figure
3 A) were treated with NaHS and rapamycin to study the effects on differentiation into mature OLGS, cell growth, and development of myelin-forming processes. Treatment with NaHS decreased (Figure 3C) but did not highly inhibit OLGs branching in contrast to what was observed through rapamycin treatment (Figure 3D) compared to control (Figure 3B). 


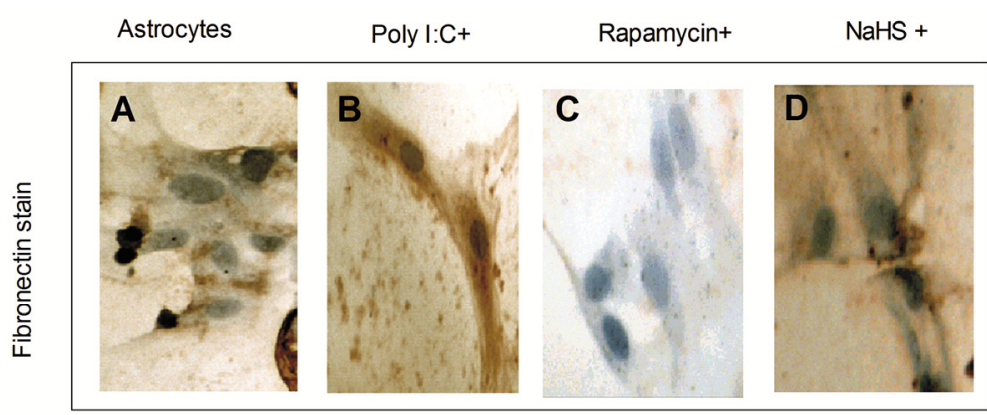

E

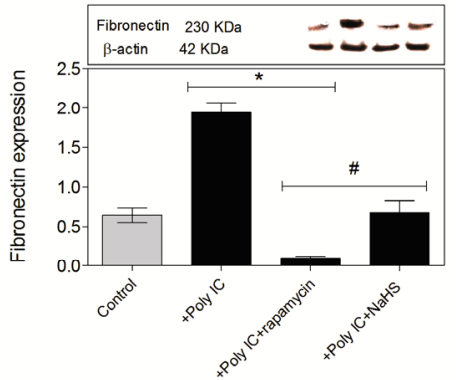

$\mathbf{F}$

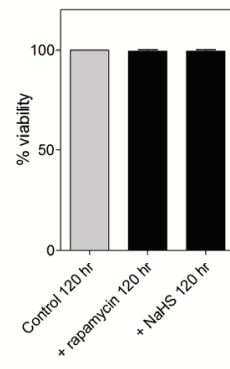

G

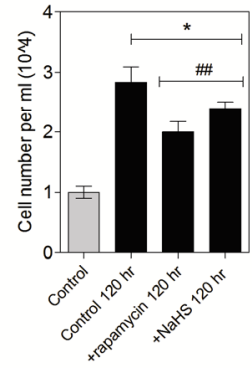

\section{NEUR:SCIENCE}

Figure 2. Immunohistochemical and Western blot analysis of fibronectin in astrocytes treated with NaHS and mTOR inhibitor rapamycin, percentage cell survival and total cell number, A) Control cells, B) Poly (I:C) (fibronectin production stimulating molecule), C) Rapamycin-treated cells, D) NaHS-treated cells, E) Western blot analysis of fibronectin expression through Poly (I:C) treatment and the effect of rapamycin and NaHS on fibronectin after Poly (I:C) treatment, F) Percentage of viable cells after NaHS and rapamycin treatment, G) Total cell number of treated astrocytes after 120 hours compared to controls.

Data are presented as means $\pm \mathrm{SD}$ ( $\mathrm{n} \geq 3$ per group in 3 replicate experiments). * Difference to control cells, \# Difference to poly (I:C) treated cells (significant difference between black bars). \#\# Difference to 120 hours control. $\mathrm{P}<0.05$. Western blot expression is normalized to $B$-actin; lanes of western blot insets are in the same order as in the X-axis.

NaHS lowered the rate but did not inhibit OPCs differentiation into OLGs and cell viability was significant but acceptable compared to rapamycin (Figure 3C, H). Rapamycin inhibited differentiation of OPCs into OLGs and highly decreased cell viability which might indicate cell growth arrest leading to cell death (Figure 3D, H). NaHS also promoted MBP expression by OLGs although at a lower level compared to control cells (Figure 3 E, G). Rapamycin-treated cells expressed low level of MBP (Figure 3F, G).

\subsection{Effects of NaHS on endothelial cells}

BBB is composed of brain endothelial cells and becomes more permeable during MS flare-up, facilitating immune cell penetration into the CNS. NaHS can reorganize HUVEC (representing ECs) cellular cytoskeleton and potentially affect cell morphology. Through NaHS treatment, HUVEC which have a more circular form (Figure 4 A) expand/relax to take a triangular island form (Figure $4 \mathrm{~B}$ ) preferentially extend motile processes (lamellipodia) from their corners and keep on expanding/relaxing to form a square expanded/ relaxed shape (Figure 4C). A control endothelial cell without NaHS treatment appears mostly spindle-shaped. It was observed that exposure to $50 \mu \mathrm{M}$ NaHS, induced the formation of protrusions in the lateral body of the cell. Following prolonged NaHS treatment, the typical lamellipodia were generated indicating the reorganization of the actin cytoskeleton. Inflammation is an important component of MS. As EC expression of heme oxygenase-1 (HO-1) as an antioxidative, anti-inflammatory factor and VCAM-1 as an adhesion molecule significantly affect inflammation, the effect of $\mathrm{NaHS}$ on HO-1 and VAM-1 expression was studied. NaHS increased HO-1 levels as an anti-inflammatory cell protective component (Figure 4 E), while inhibiting LPS-conditioned medium-induced adhesion molecule, VCAM-1 (Figure 4 F), and increasing SOCS-3 levels (Figure 4G).

The concentrations of NaHS and rapamycin used in the experiments were chosen through comparisons made between percentage survival of cells treated with different concentration of each substance and evaluation of viable cells by Trypan blue exclusion test (data not shown). The chosen concentrations showed the desired beneficial effects while providing higher cell survival. 

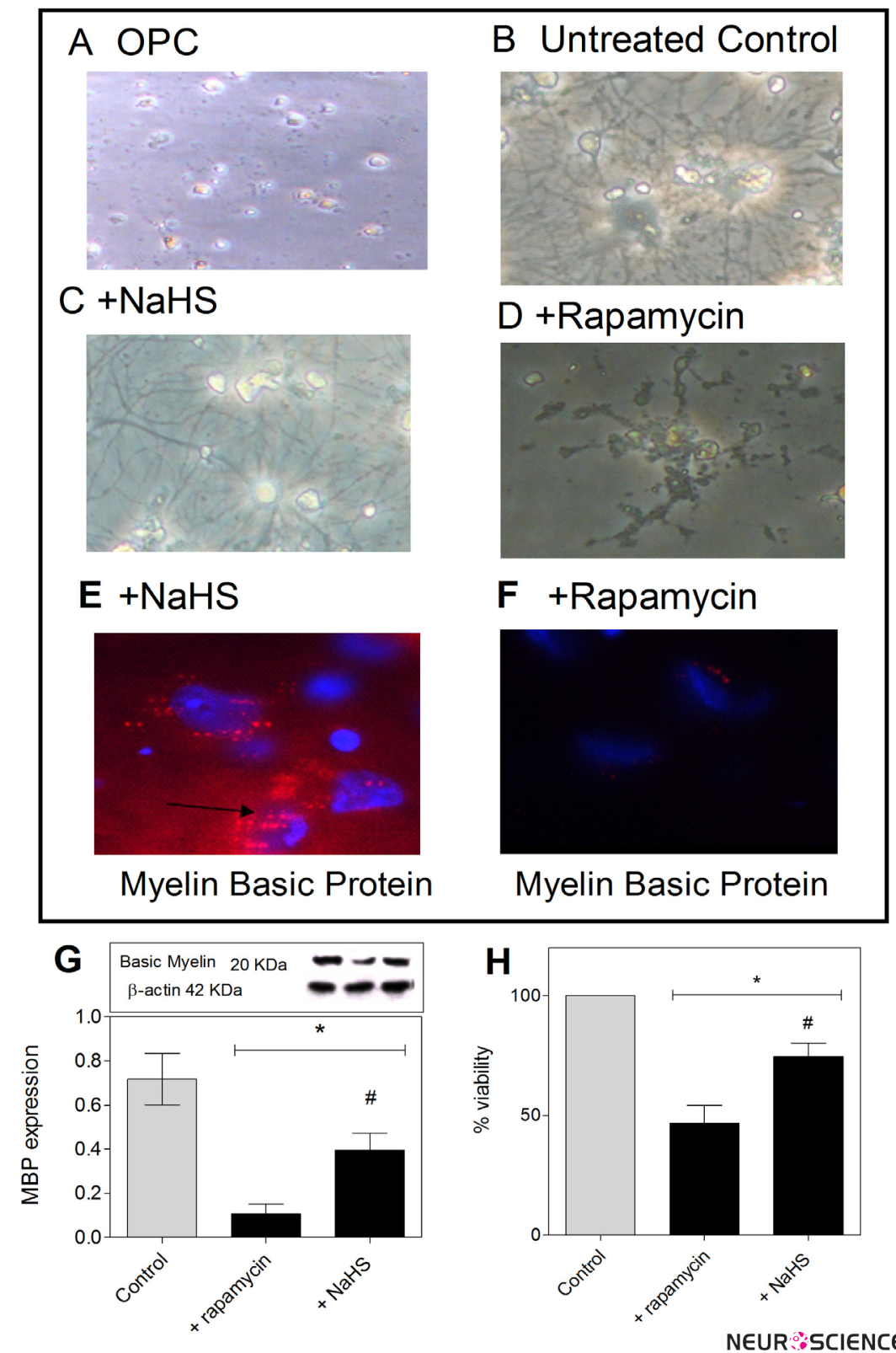

Figure 3. Differentiation of oligodendrocyte progenitor cells (OPCs) into oligodendrocytes (OLGs) shown by immunohistochemical and Western blot analysis of MBP (myelin basic protein) in OLGs treated with NaHS and mTOR inhibitor rapamycin and percentage cell survival, A) OPC, B) Oligodendrocytes, C) NaHS treated OPC through NaHS differentiate at a lower rate into oligodendrocytes with lower number of branching, D) high inhibition OPC differentiation and OLG branching by rapamycin, E) The effect of NaHS treatment on MBP expression, F) The effect of rapamycin treatment on MBP expression, G) NaHS effect on decrease in MBP expression by OLGs but to a lesser degree compared to rapamycin, $\mathrm{H}$ ) NaHS effect on lowering cell viability while rapamycin highly decreased cell viability.

Data are presented as means $\pm S D$ ( $n \geq 3$ per group in 3 replicate experiments). * Difference to normal cells. \# Difference to rapamycin treated cells (significant difference between black bars). $\mathrm{P}<0.05$. Western blot expression is normalized to $\mathrm{B}$-actin; lanes of Western blot insets are in the same order as in the $\mathrm{X}$-axis.

\section{Discussion}

This study for the first time addressed the potential use of hydrogen sulfide (as NaHS) to counteract various processes underlying MS pathology and further assessed how the 4 main cell types (oligodendrocytes, astrocytes, PBMNCs, and endothelial cells involved in MS pathophysiology) separately react to NaHS under in vivo resembling conditions through multiple experiments. For the first time, it was demonstrated that NaHS slows down but does not inhibit the differentia- 

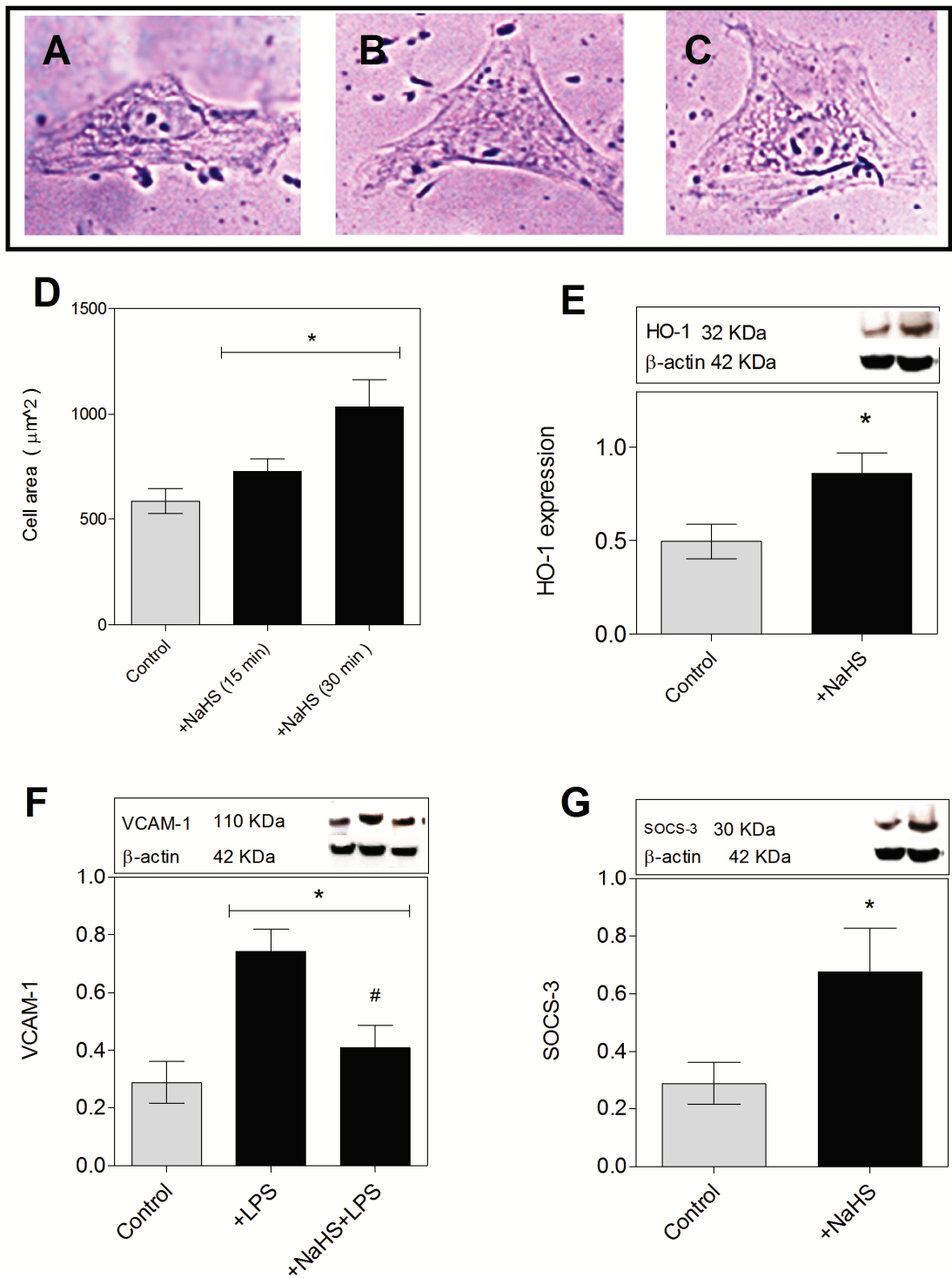

\section{NEUR:SCIENCE}

Figure 4. NaHS effects on endothelial cell morphology and expression of anti-inflammatory mediators, A) Changes of cell morphology and relaxation/expansion of HUVECs by NaHS, B) triangular island form with preferentially extending motile processes (lamellipodia) from their corners, C) the square expanded/relaxed shape (Astier, 2008), D) within 30 minutes cells occupy more space acquiring a larger cell area, E) NaHS increases HO-1 levels compared to control cells, (F) VCAM-1 expression on HUVEC after 1 hour pretreatment with NaHS and 24 hours treatment with lipopolysaccharide (LPS $100 \mathrm{ng} / \mathrm{ml}$ ), G) SOCS-3 expression through NaHS treatment.

Data are presented as means $\pm S D$ ( $n \geq 3$ per group in 3 replicate experiments). * Difference to normal cells. \# Difference to LPS treated cells (significant difference between black bars). $\mathrm{P}<0.05$. Western blot expression is normalized to ß-actin; lanes of Western blot insets are in the same order as in the $\mathrm{X}$-axis.

tion of OPCs into OLGs and subsequent myelin production, while it inhibits poly (I:C)-induced fibronectin production by astrocytes. It also inhibited PBMNCs migration in Boyden assay test induced by serotonin and conditioned medium (LPS-treated PBMNCs medium), while inducing EC morphological changes suggesting its relaxation. It was also shown for the first time that, hydrogen sulfide downregulates adhesion molecules in both PBMNCs and EC with transmigration inhibitory effects.

In the present experiments, the treatment of PBMNCs with serotonin increased cell transmigration through EC while 
NaHS inhibited transmigration. The results obtained from different studies on the effects of endogenous $\mathrm{H}_{2} \mathrm{~S}$ production on inflammatory response are contradictory. A research group suggested that the $\mathrm{H}_{2} \mathrm{~S}$, which is generated at inflammation sites, can influence the ability of neutrophils to damage tissues and it functions as a tonic regulator of leukocyte adherence to the endothelium and its permeability. But inhibition of endogenous $\mathrm{H}_{2} \mathrm{~S}$ synthesis increases leukocyte rolling and adherence to the vascular endothelium partly due to the elevated expression of adhesion molecules on leukocytes and endothelial cells (Zanardo et al., 2006). Another group has shown that inhibition of endogenous $\mathrm{H}_{2} \mathrm{~S}$ production suppresses inflammatory response (Miller et al., 2012). Furthermore, administration of exogenous $\mathrm{H}_{2} \mathrm{~S}$ has been shown to possess anti-inflammatory effects (Zanardo et al., 2006).

In the present study, it was observed that CBS knockout in PBMNCs decreased cell transmigration across EC. Indeed, CBS is known to be upregulated in activated PBMNCs (Katko et al., 2012). Surprisingly, serotonin treatment of CBS knockout PBMNCs further increased transmigration compared to serotonin-treated control cells. Serotonin has been shown to activate mTOR pathway in cells through Gprotein-coupled receptors (Santini, Heiman, Greengard, Valjent, \& Fisone, 2009) leading to upregulation of CBS and consequent higher production of $\mathrm{H}_{2} \mathrm{~S}$ (Talaei et al., 2011), while $\mathrm{H}_{2} \mathrm{~S}$ has been found to inhibit mTOR activity (Talaei et al., 2014). The relevance of mTOR pathway in the regulation of the immune system is well characterized. For example, it is essential for the proper proliferation and activation of leukocytes. Thus, the observation that $\mathrm{CBS}$ silencing decreased PBMNC transmigration, while increased the level of serotonin-induced PBMNC transmigration, is most probably pointing to a potentially delicate regulatory effect of CBS and $\mathrm{H}_{2} \mathrm{~S}$ on induced PBMNC transmigration and the involved components in immune system. This finding would suggest that inhibition of intracellular production of $\mathrm{H}_{2} \mathrm{~S}$ in PBMNCs and induction of CBS expression by serotonin have similar inhibitory effects on transmigration. It could be due to the different concentrations of $\mathrm{H}_{2} \mathrm{~S}$ at the inflammation site, inducing different cell responses such as cellular bioenergetics regulation (Modis et al., 2014; Szabo et al., 2014) affecting cell activity.

Additionally, reactive oxygen species from neutrophils produce sulfite from $\mathrm{H}_{2} \mathrm{~S}$, especially when $\mathrm{NaHS}$ is added to the supernatant of activated neutrophils (Mitsuhashi et al., 2005) creating high concentrations of this molecule. Sulfites are known to accumulate in mitochondria and highly inhibit ATP energy production, which can impair the immune system (Hong \& Pedersen, 2008), as ATP production and release promotes and guides leukocyte migration (Chen et al., 2006). Thus, leukocytes in the absence of immune system in- hibitors could lose their ability to leave the damage site where high concentrations of stimulatory factors such as serotonin are present, partly because of higher production of $\mathrm{H}_{2} \mathrm{~S}$ by these cells, which further exacerbates local tissue damage. This is also in line with the findings that $\mathrm{H}_{2} \mathrm{~S}$ at lower concentrations $(50-500 \mathrm{~nm})$ activates immune system (Miller et al., 2012) and at higher concentrations using $\mathrm{H}_{2} \mathrm{~S}$ donors, inhibits immune system (Zanardo et al., 2006). It could be due to the potential property of $\mathrm{H}_{2} \mathrm{~S}$ in regulating bioenergetics in cells through its effects on mitochondria (Szabo et al., 2014). Thus, increasing $\mathrm{H}_{2} \mathrm{~S}$ might potentially inhibit further CNS damage in MS not only as an antioxidant but also as an inhibitor of leukocyte transmigration into the CNS where these cells might become trapped and worsen the condition while potentially regulating immune system activity.

Platelet serotonin modulates steady state leukocyte rolling. It has been demonstrated that the reduced neutrophil interaction with the vessel wall in the absence of platelet serotonin leads to defective neutrophil recruitment/migration to sites of acute inflammation (Duerschmied et al., 2013). Thus, at inflammation sites and platelet accumulation/activation like plaque sites in MS, local concentrations of serotonin can greatly exceed the relatively low amounts found free in the serum (Magrini, Szabo, Doni, Cibella, \& Viola, 2011) as observed in patients with MS (Foley, Lawler, Chandran, \& Mead, 2014). Serotonin was used in our experiments to induce PBMNCs activation and transmigration firstly because of significant activation and adhesiveness of platelets in MS (Sheremata et al., 2008) and secondly because of the $\mathrm{H}_{2} \mathrm{~S}$ induction by this molecule (Talaei et al., 2011).

Migration of leukocytes and monocytes from the peripheral circulation in MS is particularly relevant in the initial phases of the disease that manifest clinically with relapses and remission dominating the pace of the MS evolution in its first decade. Serotonin induces leukocyte migration, which is suppressed by specific serotonin antagonist. Interestingly, damage to the bulbospinal serotonergic fibers occurs in patients with MS reflecting reduced levels of 5-hydroxyindoleacetic acid, a metabolite of serotonin, in the CSF of patients with MS (Deckx, Lee, Berneman, \& Cools, 2013). Thus, as patients with MS have lower levels of brain serotonin, the role of platelet serotonin at damage sites in CNS becomes even more crucial and direct modulation of platelets and platelet derived serotonin could provide a bounty of potential targets for treatment of MS (Steinman, 2012). NaHS previously shown to inhibit platelet aggregation and adhesiveness (Gao et al., 2014) could be an appropriate choice to counteract MS condition.

NaHS increases interleukin-10 (IL-10) levels in PBMNCs and downregulates integrin LFA-1. Patients with MS are 
CD46 defective, leading to IL-10 deficiency and inflammatory reactions (Astier, 2008). Thus upregulation of IL-10 is another beneficial mechanism in inhibition of leukocyteinduced inflammation in MS. $\mathrm{H}_{2} \mathrm{~S}$ could inhibit cell defense mechanisms such as neutrophil extracellular trap formation (Tillack et al., 2013), known to elevate in relapsing/remitting MS (McInturff et al., 2012). It could also downregulate integrins such as LFA-1 adhesion molecules, which bind to ICAM-1 on ECs to promote their transmigration, thus contributing to anti-inflammatory process.

In addition, NaHS upregulates suppressor of cytokine signaling 3 (SOCS-3) in PBMNCs. SOCS-3 is an important intracellular protein that inhibits cytokine signaling in numerous cell types and has been implicated in several inflammatory diseases (Yan et al., 2010). SOCS proteins, especially SOCS-1 and SOCS-3, are expressed by cells in CNS, immune cells, and vascular system cells. They possess the potential to impact immune processes within the CNS, including inflammatory cytokine and chemokine production, activation of microglia, astrocytes and macrophages, autoimmunity and immune cell infiltration. SOCS-3 negatively regulates the response of immune cells to cytokines, a classical feed-back inhibiting STAT-mediated signal transduction. Furthermore, IL-12-mediated Th1 differentiation is impaired by SOCS-3 overexpression and deletion of SOCS-3 in the hematopoietic and endothelial cell compartment is particularly associated with severe IL-1-dependent inflammatory arthritis (Wong et al., 2006). Considering different phases of disease, SOCS-3 expression is higher in PBMNCs of stable relapsing/remitting patients with MS than in PBMNC of just relapsing patients with MS (Frisullo et al., 2007). $\mathrm{H}_{2} \mathrm{~S}$ has been previously shown to upregulate SOCS-3 when supplied to protect against ventilator induced lung injury (Spassov et al., 2014). Thus, hydrogen sulfide might also play an important role in MS therapy through blockade of intracellular cytokine-signaling pathways (Tamiya, Kashiwagi, Takahashi, Yasukawa, \& Yoshimura, 2011).

Experimental autoimmune encephalomyelitis (EAE) is one of the most widely-used animal models of MS (Constantinescu, Farooqi, O’Brien, \& Gran, 2011). In both EAE and MS, lymphocytes, microglia, and macrophages release excessive amounts of glutamate, which can be neurotoxic to both neurons and oligodendrocytes (Steinman, 1999). $\mathrm{NaHS}$ is known to partially restore glutamate-depleted glutathione (GSH) levels, protecting cells from direct free radical damage induced by hydrogen peroxide probably through suppression of AMPK activation (Jia et al., 2013). In addition, the antioxidant effect of $\mathrm{H}_{2} \mathrm{~S}$ on brain cells is well documented (Talaei et al., 2014). $\mathrm{H}_{2} \mathrm{~S}$ is also known for protection of DNA of bacteria, ancestors of mitochondria (Pallen, 2011) now present in eukaryotic cells, against oxi- dative damage through phosphorothioation of DNA (Xie et al., 2012) and also protect hibernators during hibernation cycles (Talaei et al., 2012). $\mathrm{H}_{2} \mathrm{~S}$ upregulates glutamate-cysteine ligase, catalytic subunit leading to higher production of glutathione and inhibition of IL-1 $\beta$ levels (Jain, Huning, \& Micinski, 2014). This could be another beneficial effect of $\mathrm{H}_{2} \mathrm{~S}$-rich compounds in mitigating the pathogenesis of MS

In our experiments, rapamycin almost fully inhibited fibronectin production by astrocytes and OPCs differentiation into mature OLGs, while NaHS only downregulated the amount of fibronectin produced by stimulated astrocytes and slightly lowered OPCs differentiation as indicated by MBP production and taken photographs. Remyelination declines as MS progresses, resulting in chronically demyelinated plaques and axonal loss. OPCs are present in most MS lesions, but ultimately fail to differentiate into mature myelinating OLGs, resulting in remyelination failure (Franklin \& FfrenchConstant, 2008). Astrocytes engaged in inflammatory mediators gradually produce inflammation-induced extracellular matrix fibronectin aggregates in lesions where remyelination often fails. This process is crucial for functional recovery in demyelinating diseases like MS (Podbielska, Banik, Kurowska, \& Hogan, 2013). Presumably, fibronectin expression is not only due to BBB disruption and plasma leakage but also due to CNS injury of its resident cells, contributing to the fibronectin pool. Thus, a potential therapeutic substance against MS should inhibit the induced fibronectin production by astrocytes; in this regard, mTOR inhibitors could be an appropriate choice. Although fibronectin seems to have nonbeneficial effects in remyelination process, its blockade in situ with an anti-fibronectin antibody dramatically decreases outgrowth of dorsal root ganglion neuritis (Tom, Doller, Malouf, \& Silver, 2004). Thus, choosing an appropriate mTOR inhibitor could be another concern in MS therapy. In this regard, NaHS which significantly inhibits mTOR and downregulates fibronectin production (Talaei et al., 2014), without inhibiting OPCs differentiation, could be considered as a valuable molecule in inhibition of excess fibronectin production in MS without blocking repair mechanisms and myelin production.

Administration of rapamycin to cells blocks differentiation of OPCs into mature MBP producing OLGs. Therefore, activation of mTOR is essential for OPC differentiation. Specifically, mTOR regulates OLG differentiation at the late progenitor to immature OLGs transition (Tyler et al., 2009). NaHS which also inhibits mTOR (Liu et al., 2014) to a lower degree does not inhibit OPCs differentiation into mature oligodendrocytes compared to rapamycin, a strong mTOR inhibitor. Although long-term hydrogen sulfide administration at low concentration might induce nerve injury (Legator, Singleton, Morris, \& Philips, 2001; Reed, 
Crane, Garrett, Woods, \& Bates, 2014), its administration at controlled concentrations promotes proliferation and neuronal differentiation of neural stem cells and protects hypoxia-induced decrease in hippocampal neurogenesis (Liu et al., 2014). Furthermore, NaHS increases Akt phosphorylation (Talaei et al., 2014; Wang et al., 2010), which could be beneficial in protecting brain cells against potential damages and promote cell proliferation.

Although microglia/macrophages phagocytosis of antigens is the hallmark of MS lesions, the type of cell death and extent of tissue damage dictate the subsequent MS associated innate responses to the oligodendrocytes damage. A therapeutic challenge in MS is how to modulate the dynamic properties of microglia/macrophages so as to limit potentially damaging innate responses and provide local recovery (Jack, Ruffini, Bar-Or, \& Antel, 2005). Interestingly, hydrogen sulfide has been used to inhibit neurotoxic microglia activation that consequently provides neuroprotection (Zhang, \& Wang, 2014), which could be beneficial in limiting CNS damage in MS.

Adhesion molecules and cytokines are known to be upregulated in MS. NaHS downregulates adhesion molecule VCAM-1 on endothelial cells while upregulates HO-1 and SOCS-3 levels. HO-1 modulates the expression of adhesion molecules associated with EC activation and its overexpression in EC inhibits TNF- $\alpha$-mediated VCAM-1 expression (Soares et al., 2004). BBB becomes permeable during MS attack and EC morphology is known to change through stimulation (Parker \& Ingber, 2007). In this study, NaHS treatment increased EC diameter in vitro which in turn could decrease intracellular spaces between the ECs. These processes taken together would partially inhibit leukocyte binding, rolling, and transmigration. It has been proposed that Rho GTPase Racl activation mediates $\mathrm{H}_{2} \mathrm{~S}$ promoted endothelial cell migration via actin cytoskeleton reorganization and has pivotal role in angiogenesis (Zhang, Tao, Wang, Jin, \& Zhu, 2012). EC morphology changes through NaHS treatment as cells attach to the bottom of the Petri dish expand or relax and increase in diameter, most probably due to the effects of NaHS on actin cytoskeleton reorganization and cell-matrix adhesiveness (Astier, 2008). In vivo, leukocyte transendothelial migration (TEM) occurs at endothelial cell junctions (paracellular) and nonjunctional (transcellular) locations, whereas in vitro models TEM is mostly paracellular (Yang et al., 2005). This could be related to lower PBMNCs transmigration through NaHS treatment in the previously explained Boyden assay. Apparently, higher hydrogen sulfide levels in vivo setting would also decrease BBB permeability and counteract higher BBB permeability observed during MS attack.
MS is not just an autoimmune disease. In addition to demyelination and inflammation, the pathological features include neuronal and axonal injury and loss which underlie the disease progression and the accumulation of disability (Arnon \& Aharoni, 2009). Thus, specific treatment strategies should target the injury sites at CNS to interfere with both neurodegeneration and neuroinflammation. While hydrogen sulfide shows appropriate properties to be incorporated as a potential MS treatment, it has a short half life and acts only close to the sites of its production. Furthermore, treatments with $\mathrm{H}_{2} \mathrm{~S}$ releasing molecules, which would increase its systemic presence, seems to be inappropriate as these molecules spread all over the body causing side effects before achieving their beneficial effects at the injury sites. This situation requires the development of appropriate targeted and controlled release drug delivery systems, an essential step in incorporating $\mathrm{H}_{2} \mathrm{~S}$ releasing molecules in vivo.

The results of this research points out the potential therapeutic application of hydrogen sulfide and health-promoting sulfur compounds in MS, its known beneficial properties on different cellular components, and endogenous and exogenous $\mathrm{H}_{2} \mathrm{~S}$ effects on immune system. Further, this could point to the potential beneficial effects of nutritional sulfur products such as methylsulfonylmethane, a water soluble organosulfur obtained through oxidation of dimethyl sulfoxide, in MS. These findings may be the first step towards developing potentially effective and specific novel therapies against this disease and its complications by using $\mathrm{H}_{2} \mathrm{~S}$ releasing molecules and further strengthening the development and applicability of nutritional sulfur products to beneficially modulate the molecular mechanisms in the main cell types involved in MS pathophysiology.

\section{Conflict of Interests}

The author declared that the research was conducted in the absence of any commercial or financial interests that could be construed as a potential conflict of interest.

\section{References}

Alirezaei, M., Kemball, C. C., \& Whitton, J. L. (2011). Autophagy, inflammation and neurodegenerative disease. The European Journal of Neuroscience, 33(2), 197-204. doi:10.1111/j.1460-9568.2010.07500.x.

Arnon, R., \& Aharoni, R. (2009). Neuroprotection and neurogeneration in MS and its animal model EAE effected by glatiramer acetate. Journal of Neural Transmission, 116(11), 1443-1449. doi:10.1007/ s00702-009-0272-3. 
Astier, A. L. (2008). T-cell regulation by CD46 and its relevance in multiple sclerosis. Immunology, 124(2), 149-154. doi:10.1111/j.13652567.2008.02821.x.

Bradford, M. M. (1976). A rapid and sensitive method for the quantitation of microgram quantities of protein utilizing the principle of protein-dye binding. Analytical Biochemistry, 72(1), 248-254.

Bsibsi, M., Nomden, A., van Noort, J. M., \& Baron, W. (2012). Tolllike receptors 2 and 3 agonists differentially affect oligodendrocyte survival, differentiation, and myelin membrane formation. Journal of Neuroscience Research, 90(2), 388-398. doi:10.1002/jnr.22767.

Bsibsi, M., Ravid, R., Gveric, D., \& van Noort, J. M. (2002). Broad expression of toll-like receptors in the human central nervous system. Journal of Neuropathology and Experimental Neurology, 61(11), 1013-1021.

Carlson, N. G., \& Rose, J. W. (2006). Antioxidants in multiple sclerosis: Do they have a role in therapy? CNS Drugs, 20(6), 433-441.

Chen, Y., Corriden, R., Inoue, Y., Yip, L., Hashiguchi, N., Zinkernagel, A., et al. (2006). ATP release guides neutrophil chemotaxis via P2Y2 and A3 receptors. Science, 314(5806), 1792-1795. doi:314/5806/1792.

Constantinescu, C. S., Farooqi, N., O'Brien, K., \& Gran, B. (2011). Experimental autoimmune encephalomyelitis (EAE) as a model for multiple sclerosis (MS). British Journal of Pharmacology, 164(4), 1079-1106. doi:10.1111/j.1476-5381.2011.01302.x.

Crampton, S. P., Davis, J., \& Hughes, C. C. (2007). Isolation of human umbilical vein endothelial cells (HUVEC). Journal of Visualized Experiments, 3, 183 .

Deckx, N., Lee, W. P., Berneman, Z. N., \& Cools, N. (2013). Neuroendocrine immunoregulation in multiple sclerosis. Clinical \& Developmental Immunology, 2013, 705232. doi:10.1155/2013/705232.

Dello Russo, C., Lisi, L., Feinstein, D. L., \& Navarra, P. (2013). mTOR kinase, a key player in the regulation of glial functions: Relevance for the therapy of multiple sclerosis. Glia, 61(3), 301-311. doi:10.1002/glia.22433

Duerschmied, D., Suidan, G. L., Demers, M., Herr, N., Carbo, C., Brill, A., et al. (2013). Platelet serotonin promotes the recruitment of neutrophils to sites of acute inflammation in mice. Blood, 121(6), 1008-1015. doi:10.1182/blood-2012-06-437392

Foley, P., Lawler, A., Chandran, S., \& Mead, G. (2014). Potential disease-modifying effects of selective serotonin reuptake inhibitors in multiple sclerosis: Systematic review and meta-analysis. Journal of Neurology, Neurosurgery, and Psychiatry, 85(6), 709-710. doi:10.1136/jnnp-2013-306829.

Franklin, R. J., \& Ffrench-Constant, C. (2008). Remyelination in the CNS: From biology to therapy. Nature Reviews Neuroscience, 9(11), 839-855. doi:10.1038/nrn2480.

Frisullo, G., Mirabella, M., Angelucci, F., Caggiula, M., Morosetti, R. Sancricca, C., et al. (2007). The effect of disease activity on leptin, leptin receptor and suppressor of cytokine signalling-3 expression in relapsing-remitting multiple sclerosis. Journal of Neuroimmunology, 192(1-2), 174-183. doi:S0165-5728(07)00295-0.

Hong, S., \& Pedersen, P. L. (2008). ATP synthase and the actions of inhibitors utilized to study its roles in human health, disease, and other scientific areas. Microbiology and Molecular Biology Reviews, 72(4), 590-641. doi:10.1128/MMBR.00016-08.
Ineichen, B. V., Keskitalo, S., Farkas, M., Bain, N., Kallweit, U., Weller, M., et al. (2014). Genetic variants of homocysteine metabolism and multiple sclerosis: A case-control study. Neuroscience Letters, 562, 75-78. doi:10.1016/j.neulet.2014.01.008.

Jack, C., Ruffini, F., Bar-Or, A., \& Antel, J. P. (2005). Microglia and multiple sclerosis. Journal of Neuroscience Research, 81(3), 363-373. doi:10.1002/jnr.20482.

Jain, S. K., Huning, L., \& Micinski, D. (2014). Hydrogen sulfide upregulates glutamate-cysteine ligase catalytic subunit, glutamatecysteine ligase modifier subunit, and glutathione and inhibits interleukin-1beta secretion in monocytes exposed to high glucose levels. Metabolic Syndrome and Related Disorders, 12(5), 299-302. doi:10.1089/met.2014.0022.

Jia, J., Xiao, Y., Wang, W., Qing, L., Xu, Y., Song, H., et al. (2013) Differential mechanisms underlying neuroprotection of hydrogen sulfide donors against oxidative stress. Neurochemistry International, 62(8), 1072-1078. doi:10.1016/j.neuint.2013.04.001.

Kamath, A. F., Chauhan, A. K., Kisucka, J., Dole, V. S., Loscalzo, J., Handy, D. E., et al. (2006). Elevated levels of homocysteine compromise blood-brain barrier integrity in mice. Blood, 107(2), 591593. doi:2005-06-2506

Katko, M., Zavaczki, E., Jeney, V., Paragh, G., Balla, J., \& Varga, Z. (2012). Homocysteine metabolism in peripheral blood mononuclear cells: Evidence for cystathionine beta-synthase activity in resting state. Amino Acids, 43(1), 317-326. doi:10.1007/s00726-0111080-2.

Kitagishi, Y., Kobayashi, M., Kikuta, K., \& Matsuda, S. (2012) Roles of PI3K/AKT/GSK3/mTOR pathway in cell signaling of mental illnesses. Depression Research and Treatment, 2012, 752563. doi:10.1155/2012/752563.

Langer, H. F., Choi, E. Y., Zhou, H., Schleicher, R., Chung, K. J., Tang, Z., et al. (2012). Platelets contribute to the pathogenesis of experimental autoimmune encephalomyelitis. Circulation Research 110(9), 1202-1210. doi:10.1161/CIRCRESAHA.111.256370.

Legator, M. S., Singleton, C. R., Morris, D. L., \& Philips, D. L. (2001). Health effects from chronic low-level exposure to hydrogen sulfide. Archives of Environmental Health, 56(2), 123-131. doi:10.1080/00039890109604063 [doi]

Lisi, L., Navarra, P., Feinstein, D. L., \& Dello Russo, C. (2011). The mTOR kinase inhibitor rapamycin decreases iNOS mRNA stability in astrocytes. Journal of Neuroinflammation, 8(1), 1-2094-8-1. doi:10.1186/1742-2094-8-1.

Liu, D., Wang, Z., Zhan, J., Zhang, Q., Wang, J., Zhang, Q., et al. (2014). Hydrogen sulfide promotes proliferation and neuronal differentiation of neural stem cells and protects hypoxia-induced decrease in hippocampal neurogenesis. Pharmacology, Biochemistry, and Behavior, 116, 55-63. doi:10.1016/j.pbb.2013.11.009.

Magrini, E., Szabo, I., Doni, A., Cibella, J., \& Viola, A. (2011). Serotonin-mediated tuning of human helper $\mathrm{T}$ cell responsiveness to the chemokine CXCL12. PloS One, 6(8), 22482. doi:10.1371/journal. pone.0022482

Maier, O., Baron, W., \& Hoekstra, D. (2007). Reduced raft-association of NF155 in active MS-lesions is accompanied by the disruption of the paranodal junction. Glia, 55(8), 885-895. doi:10.1002/glia.20510.

Maier, O., van der Heide, T., van Dam, A., Baron, W., de Vries, H. \& Hoekstra, D. (2005). Alteration of the extracellular matrix interferes with raft association of neurofascin in oligodendrocytes. 
Potential significance for multiple sclerosis? Molecular and Cellular Neuroscience, 28(2), 390-401. doi: 10.1016/j.mcn.2004.09.012.

Man, S., Ubogu, E. E., Williams, K. A., Tucky, B., Callahan, M. K., \& Ransohoff, R. M. (2008). Human brain microvascular endothelial cells and umbilical vein endothelial cells differentially facilitate leukocyte recruitment and utilize chemokines for T cell migration. Clinical \& Developmental Immunology, 2008, 384982 doi:10.1155/2008/384982

Matute, C., Alberdi, E., Domercq, M., Sanchez-Gomez, M. V., PerezSamartin, A., Rodriguez-Antiguedad, A., et al. (2007). Excitotoxic damage to white matter. Journal of Anatomy, 210(6), 693-702.

McInturff, A. M., Cody, M. J., Elliott, E. A., Glenn, J. W., Rowley, J. W., Rondina, M. T., et al. (2012). Mammalian target of rapamycin regulates neutrophil extracellular trap formation via induction of hypoxia-inducible factor 1 alpha. Blood, 120(15), 3118-3125. doi:10.1182/blood-2012-01-405993.

Miljkovic, D., \& Spasojevic, I. (2013). Multiple sclerosis: Molecular mechanisms and therapeutic opportunities. Antioxidants $\mathcal{E}$ Redox Signaling, 19(18), 2286-2334. doi:10.1089/ars.2012.5068.

Miller, T. W., Wang, E. A., Gould, S., Stein, E. V., Kaur, S., Lim, L., et al. (2012). Hydrogen sulfide is an endogenous potentiator of $\mathrm{T}$ cell activation. Journal of Biological Chemistry, 287(6), 4211-4221. doi:10.1074/jbc.M111.307819 [doi]

Mitsuhashi, H., Yamashita, S., Ikeuchi, H., Kuroiwa, T., Kaneko, Y., Hiromura, K., et al. (2005). Oxidative stress-dependent conversion of hydrogen sulfide to sulfite by activated neutrophils. Shock, 24(6), 529-534. doi:00024382-200512000-00007.

Modis, K., Bos, E. M., Calzia, E., van Goor, H., Coletta, C., Papapetropoulos, A., et al. (2014). Regulation of mitochondrial bioenergetic function by hydrogen sulfide. Part II: Pathophysiological and therapeutic aspects. British Journal of Pharmacology, 171(8), 21232146. doi:10.1111/bph.12368.

Pallen, M. J. (2011). Time to recognize that mitochondria are bacteria? Trends in Microbiology, 19(2), 58-64. doi:10.1016/j.tim.2010.11.001.

Panda, S. K., Kumar, S., Tupperwar, N. C., Vaidya, T., George, A., Rath, S., et al. (2012). Chitohexaose activates macrophages by alternate pathway through TLR4 and blocks endotoxemia. PLoS Pathogens, 8(5), e1002717. doi:10.1371/journal.ppat.1002717.

Parker, K. K., \& Ingber, D. E. (2007). Extracellular matrix, mechanotransduction and structural hierarchies in heart tissue engineering. Philosophical Transactions of the Royal Society of London Series B: Biological Sciences, 362(1484), 1267-1279. doi:1L11388X23G27776.

Podbielska, M., Banik, N. L., Kurowska, E., \& Hogan, E. L. (2013) Myelin recovery in multiple sclerosis: The challenge of remyelination. Brain Sciences, 3(3), 1282-1324. doi:10.3390/brainsci3031282.

Reed, B. R., Crane, J., Garrett, N., Woods, D. L., \& Bates, M. N. (2014). Chronic ambient hydrogen sulfide exposure and cognitive function. Neurotoxicology and Teratology, 42, 68-76. doi:10.1016/j. ntt.2014.02.002.

Santini, E., Heiman, M., Greengard, P., Valjent, E., \& Fisone, G. (2009). Inhibition of mTOR signaling in Parkinson's disease prevents L-DOPA-induced dyskinesia. Science Signaling, 2(80), 36 doi:10.1126/scisignal.2000308.

Sheremata, W. A., Jy, W., Horstman, L. L., Ahn, Y. S., Alexander, J. S., \& Minagar, A. (2008). Evidence of platelet activation in multiple sclerosis. Journal of Neuroinflammation, 5(27), 2094-5. doi:10.1186/1742-2094-5-27.
Soares, M. P., Seldon, M. P., Gregoire, I. P., Vassilevskaia, T., Berberat, P. O., Yu, J., et al. (2004). Heme oxygenase-1 modulates the expression of adhesion molecules associated with endothelial cell activation. Journal of Immunology, 172(6), 3553-3563

Spassov, S., Pfeifer, D., Strosing, K., Ryter, S., Hummel, M., Faller, S., et al. (2014). Genetic targets of hydrogen sulfide in ventilatorinduced lung injury-a microarray study. PloS One, 9(7), e102401. doi:10.1371/journal.pone.0102401.

Steinman, L. (1999). Assessment of animal models for MS and demyelinating disease in the design of rational therapy. Neuron, 24(3), 511-514. doi:S0896-6273(00)81107-1.

Steinman, L. (2012). Platelets provide a bounty of potential targets for therapy in multiple sclerosis. Circulation Research, 110(9), 11571158. doi:10.1161/CIRCRESAHA.112.269050.

Stephenson, E., Nathoo, N., Mahjoub, Y., Dunn, J. F., \& Yong, V. W. (2014). Iron in multiple sclerosis: Roles in neurodegeneration and repair. Nature Reviews Neurology, 10(8), 459-468. doi:10.1038/ nrneurol.2014.118.

Szabo, C., Ransy, C., Modis, K., Andriamihaja, M., Murghes, B. Coletta, C., et al. (2014). Regulation of mitochondrial bioenergetic function by hydrogen sulfide. Part I. biochemical and physiological mechanisms. British Journal of Pharmacology, 171(8), 2099-2122. doi:10.1111/bph.12369.

Talaei, F., Bouma, H., Van der Graaf, A., Strijkstra, A., Schmidt, M., \& Henning, R. (2011). Serotonin and dopamine protect from Hypothermia/Rewarming damage through the CBS/ $\mathrm{H}_{2} \mathrm{~S}$ pathway. PLoS ONE, 6(7), 22568. doi:10.1371/journal.pone.0022568.

Talaei, F. (2014). Modulation of mTOR and autophagy in hibernating hamster lung and the application of the potential mechanism to improve the recellularization process of decellularized lung scaffolds. Journal of Regenerative Medicine and Tissue Engineering, 3(1), 1 .

Talaei, F., Bouma, H. R., Hylkema, M. N., Strijkstra, A. M., Boerema, A. S., Schmidt, M., et al. (2012). The role of endogenous $\mathrm{H}_{2} \mathrm{~S}$ formation in reversible remodeling of lung tissue during hibernation in the Syrian hamster. Journal of Experimental Biology, 215(Pt 16), 2912 2919. doi:10.1242/jeb.067363.

Talaei, F., Van Praag, V. M., Shishavan, M. H., Landheer, S. W. Buikema, H., \& Henning, R. H. (2014). Increased protein aggregation in zucker diabetic fatty rat brain: Identification of key mechanistic targets and the therapeutic application of hydrogen sulfide. BMC Cell Biology, 15(1), 1. doi:10.1186/1471-2121-15-1.

Talaei, F. (2012). Aberrations in proteostasis orchestrate: The genotypic and phenotypic changes in aging. American Journal of Molecular and Cellular Biology, 1(1), 1-16. doi:10.7726/ajmcb.2012.1001.

Tamiya, T., Kashiwagi, I., Takahashi, R., Yasukawa, H., \& Yoshimura, A. (2011). Suppressors of cytokine signaling (SOCS) proteins and JAK/STAT pathways: Regulation of T-cell inflammation by SOCS1 and SOCS3. Arteriosclerosis, Thrombosis, and Vascular Biol ogy, 31(5), 980-985. doi:10.1161/ATVBAHA.110.207464

Tillack, K., Naegele, M., Haueis, C., Schippling, S., Wandinger, K. P. Martin, R., \& Sospedra, M. (2013). Gender differences in circulating levels of neutrophil extracellular traps in serum of multiple sclerosis patients. Journal of Neuroimmunology, 261(1-2), 108-119. doi:10.1016/j.jneuroim.2013.05.004.

Tom, V. J., Doller, C. M., Malouf, A. T., \& Silver, J. (2004). Astrocyte-associated fibronectin is critical for axonal regeneration in 
adult white matter. Journal of Neuroscience, 24(42), 9282-9290. doi:24/42/9282.

Tyler, W. A., Gangoli, N., Gokina, P., Kim, H. A., Covey, M., Levison, S. W., \& Wood, T. L. (2009). Activation of the mammalian target of rapamycin (mTOR) is essential for oligodendrocyte differentiation. Journal of Neuroscience, 29(19), 6367-6378. doi:10.1523/JNEU3 ROSCI.0234-09.2009.

Wang, M. J., Cai, W. J., Li, N., Ding, Y. J., Chen, Y., \& Zhu, Y. C. (2010). The hydrogen sulfide donor NaHS promotes angiogenesis in a rat model of hind limb ischemia. Antioxidants \& Redox Signaling, 12(9), 1065-1077. doi:10.1089/ars.2009.2945.

Waubant, E. (2006). Biomarkers indicative of blood-brain barrier disruption in multiple sclerosis. Disease Markers, 22(4), 235-244.

Wong, P. K., Egan, P. J., Croker, B. A., O'Donnell, K., Sims, N. A. Drake, S., et al. (2006). SOCS-3 negatively regulates innate and adaptive immune mechanisms in acute IL-1-dependent inflammatory arthritis. Journal of Clinical Investigation, 116(6), 1571-1581. doi:10.1172/JCI25660.

Xie, X., Liang, J., Pu, T., Xu, F., Yao, F., Yang, Y., et al. (2012). Phosphorothioate DNA as an antioxidant in bacteria. Nucleic Acids Research, 40(18), 9115-9124. doi:10.1093/nar/gks650.

Yan, C., Cao, J., Wu, M., Zhang, W., Jiang, T., Yoshimura, A., \& Gao, H. (2010). Suppressor of cytokine signaling 3 inhibits LPS-induced IL-6 expression in osteoblasts by suppressing CCAAT/Enhancerbinding protein $B$ activity. Journal of Biological Chemistry, 285(48), 37227-37239. doi:10.1074/jbc.M110.132084.

Yang, L., Froio, R. M., Sciuto, T. E., Dvorak, A. M., Alon, R., \& Luscinskas, F. W. (2005). ICAM-1 regulates neutrophil adhesion and transcellular migration of TNF-alpha-activated vascular endothelium under flow. Blood, 106(2), 584-592. doi:2004-12-4942.

Zanardo, R. C., Brancaleone, V., Distrutti, E., Fiorucci, S., Cirino, G., \& Wallace, J. L. (2006). Hydrogen sulfide is an endogenous modulator of leukocyte-mediated inflammation. The FASEB Journal: Official Publication of the Federation of American Societies for Experimental Biology, 20(12), 2118-2120. doi:10.1096/fj.06-6270fje

Zhang, L. J., Tao, B. B., Wang, M. J., Jin, H. M., \& Zhu, Y. C. (2012) PI3K p110alpha isoform-dependent rho GTPase Rac1 activation mediates $\mathrm{H}_{2} \mathrm{~S}$-promoted endothelial cell migration via actin cytoskeleton reorganization. PloS One, 7(9), e44590. doi:10.1371/ journal.pone.0044590.

Zhang, Q., Yuan, L., Liu, D., Wang, J., Wang, S., Zhang, Q., et al (2014). Hydrogen sulfide attenuates hypoxia-induced neurotoxicity through inhibiting microglial activation. Pharmacological Research, 84, 32-44. doi:10.1016/j.phrs.2014.04.009. 
